\title{
Depression and Cardiovascular Disease:
}

\author{
Healing the Broken-Hearted
}

Mary A. Whooley, MD

Veterans Affairs Medical Center and University of California, San Francisco Medical Center.

\begin{abstract}
Major depressive disorder is a risk factor for the development of incident coronary heart disease events in healthy patients and for adverse cardiovascular outcomes in patients with established heart disease. Depression is present in 1 of 5 outpatients with coronary heart disease and in 1 of 3 outpatients with congestive heart failure, yet the majority of cases are not recognized or appropriately treated. It is not known whether treating depression improves cardiovascular outcomes, but antidepressant treatment with selective serotonin reuptake inhibitors is generally safe, alleviates depression, and improves quality of life. This article evaluates the importance of major depression in patients with cardiovascular disease, and provides practical guidance for identifying and treating this disorder.
\end{abstract}

\section{CASE PRESENTATION}

A 58-year-old man with a history of coronary heart disease (CHD), type 2 diabetes mellitus, hypertension, smoking, and alcohol dependence presented for routine medical care. He had initially sought medical attention for exertional angina 5 years previously, at which time he underwent exercise treadmill testing with thallium that was positive for reversible perfusion defects in the anterior, septal, and inferior walls. Subsequent coronary angiography revealed diffuse heavy calcifications in the left anterior descending artery with a moderate lesion prior to the first diagonal. Several major septal perforators had significant lesions at their origins. In the dominant right coronary artery, there were diffuse calcifications but no significant lesions. The left circumflex and large ramus intermedius were free of discrete lesions. Left ventricular function was normal.

The patient underwent single-vessel (left internal mammary artery to left anterior descending artery) coronary artery bypass grafting (CABG) surgery. He was prescribed atenolol $100 \mathrm{mg} /$ $\mathrm{d}$, lisinopril $40 \mathrm{mg} / \mathrm{d}$, lovastatin $80 \mathrm{mg} / \mathrm{d}$, aspirin $325 \mathrm{mg} / \mathrm{d}$, metformin $850 \mathrm{mg} 3$ times a day, and glipizide $10 \mathrm{mg} 2$ times a day. Despite being nonadherent to his prescribed medications, he remained stable for 5 years, but then one day, while doing household chores, he suddenly developed chest pressure, shortness of breath, and diaphoresis that lasted 12 hours. On admission to the hospital his troponin I was elevated and peaked at $0.7 \mathrm{ng} / \mathrm{mL}$ (normal, $<0.05$ $\mathrm{ng} / \mathrm{mL}$ ), consistent with a myocardial infarction (MI). His electrocardiogram had not changed.

(C)2006 American Medical Association. All rights reserved.

Corresponding Author: Mary A. Whooley, MD, Veterans Affairs Medical Center and University of California, San Francisco, 4150 Clement Street (111A1), San Francisco, CA 94121 (mary.whooley@ucsf.edu)..

Financial Disclosure: None reported.

Previous Presentation: This conference took place at the Medicine Grand Rounds of the University of California, San Francisco, on July 21, 2005.

Grand Rounds at the University of California, San Francisco Medical Center: David S. Cooper, MD, Contributing Editor, JAMA. 
Coronary angiography revealed a new $95 \%$ critical proximal right coronary artery lesion in the dominant vessel as well as $80 \%$ lesions in the first posterior lateral branch and posterior descending artery.

The patient received a taxol-eluting stent in the proximal right coronary artery and percutaneous transluminal coronary angioplasty of the first posterior lateral branch and posterior descending artery. His discharge medications were clopidogrel $75 \mathrm{mg} / \mathrm{d}$, metoprolol $100 \mathrm{mg}$ twice daily, lisinopril $40 \mathrm{mg}$ daily, lovastatin $80 \mathrm{mg} / \mathrm{d}$, aspirin $325 \mathrm{mg} / \mathrm{d}$, metformin $850 \mathrm{mg} 3$ times daily, rosiglitazone $8 \mathrm{mg} / \mathrm{d}$, and glipizide $10 \mathrm{mg}$ twice daily. When he presented 2 months later for routine care, the patient stated that, although his angina had resolved, he had no energy and was sleeping all the time. Upon further questioning, he reported several weeks of depressed mood, lack of interest in his usual activities, and poor concentration. He also acknowledged that he had experienced this same constellation of symptoms on and off for weeks at a time ever since his CABG surgery 5 years earlier. He denied suicidal thoughts. A diagnosis of recurrent major depressive disorder was made.

\section{Did Depression Increase This Patient's Risk for a Recurrent Cardiac Event?}

Major depressive disorder and cardiovascular disease are the 2 leading causes of worldwide disability ${ }^{1}$ and among the top 5 chronic disorders encountered in the care of older patients. ${ }^{2}$ Numerous - though not all—studies suggest that major depressive disorder, and even subthreshold depressive symptoms that do not meet the criteria for a diagnosis of major depressive disorder (henceforth referred to as depression), ${ }^{3}$ are risk factors for the development of CHD events in healthy patients, ${ }^{4}$ for recurrent events in patients with established CHD, ${ }^{5-8}$ and for adverse cardiovascular outcomes after CABG surgery. ${ }^{9}$

Depression may itself be caused by greater severity of clinical CHD, but the increased risk of adverse cardiovascular events associated with depression appears to be independent of age, diabetes, smoking, lipid levels, obesity, physical activity, and baseline severity of heart disease. The recent INTERHEART study sought to identify modifiable risk factors for acute MI in more than 25000 patients from 52 countries. ${ }^{10}$ As expected, the traditional risk factors of dyslipidemia, diabetes, smoking, hypertension, and obesity were all predicitive of acute MI and protective effects were observed for exercise, regular alcohol use, and intake of fruit and vegetables. However, in a multivariable model, psychosocial factors were stronger risk factors for incident MI than diabetes, smoking, hypertension, and obesity. ${ }^{10}$

Depression has also been associated with the development of congestive heart failure (CHF) 11,12 and with adverse outcomes in patients with CHF. ${ }^{13-15}$ In a study examining incidence of CHF among 4500 patients who were enrolled in the Systolic Hypertension in the Elderly Program, the cumulative incidence of CHF in the depressed patients was $16 \%$, whereas the incidence was only $7 \%$ in the nondepressed group. ${ }^{11}$ This resulted in an overall relative risk of 2.6 after adjustment for traditional cardiovascular risk factors. In patients with established CHF, depression further predicts mortality and rehospitalization, independent of baseline ventricular function and severity of cardiovascular disease. ${ }^{13}$

\section{How Might Depression Lead to Cardiac Events?}

Several biological and behavioral factors have been identified as candidate mechanisms by which depression may lead to cardiac events (Box). ${ }^{31-33}$ All of these potential mediators have been linked with both depression and cardiac events. However, no study has determined which - or what combination — of these possible mechanisms explains the association of depression with adverse cardiovascular outcomes. In the case presented, the patient was nonadherent to the cardiovascular medications that he was prescribed following CABG surgery. Because depression is associated with medication nonadherence and because preventive medications 
decrease morbidity and mortality in patients with cardiovascular disease, ${ }^{34-36}$ it is possible that depression and its associated medication nonadherence contributed to this patient's MI.

Medication nonadherence may also be a marker of other unhealthy behaviors that increase risk of cardiac events in depressed patients. 26,30

\section{Can Treating Depression Prevent Cardiac Events?}

Treatment for depression is necessary because it alleviates depressive symptoms ${ }^{37}$ and improves quality of life. ${ }^{38}$ Whether antidepressant therapy improves cardiovascular outcomes is not known. This question is important because all prior evidence supporting an effect of depression on risk of cardiovascular events comes from observational studies. Although the association of depression with adverse cardiovascular outcomes is strong, dose-dependent, biologically plausible, temporal, and independent of traditional cardiovascular risk factors, 4 , 6-9 it is impossible to completely exclude residual confounding in observational studies. ${ }^{39}$ Thus, a randomized trial demonstrating that treatment for depression improves cardiovascular outcomes would be necessary to prove a causal association.

\section{Does Pharmacotherapy for Depression Prevent Cardiac Events?}

The Sertraline Antidepressant Heart Attack Randomized Trial (SADHART) is to date the largest randomized trial evaluating use of an antidepressant medication for depressed patients with heart disease..$^{40} \mathrm{~A}$ total of 369 participants who had depression after hospitalization for acute coronary syndrome were randomly assigned to the selective serotonin reuptake inhibitor (SSRI) antidepressant medication sertraline vs placebo. Of these, 260 completed the 16-week trial. Investigators found no difference in safety (change in left ventricular ejection fraction, increase in premature ventricular contractions, or prolongation of the QT interval) between the treatment and placebo groups. Although SADHART was designed as a safety trial and was not powered to evaluate cardiovascular events, investigators found a non-significant reduction in the composite end point (MI or CHD death) in the sertraline group (relative risk, $0.77 ; 95 \%$ confidence interval, 0.51-1.16). These results were intriguing because evidence suggests that SSRIs may be directly cardioprotective by reducing platelet activation. ${ }^{41}$ However, a larger trial is needed to evaluate the potential benefits of SSRI medication on cardiovascular outcomes in patients with CHD.

Box

\section{Mechanisms by Which Depression May Lead to Cardiac Events}

Potential biological mechanisms

Alterations in cardiac autonomic tone $\mathrm{e}^{16}$

Common genetic vulnerability ${ }^{17}$

Enhanced activity of the hypothalamic pituitary-axis ${ }^{18}$

Greater platelet activation ${ }^{19}$

Increased catecholamine levels ${ }^{20}$

Increased whole blood serotonin ${ }^{21}$

Inflammatory processes ${ }^{22}$

Lower omega-3 fatty acid levels ${ }^{23}$

Mental-stress induced ischemia ${ }^{24}$

Toxicity of tricyclic antidepressants ${ }^{25}$ 
Potential behavioral mechanisms

Dietary factors 26

Lack of exercise ${ }^{27}$

Medication nonadherence ${ }^{28}$

Poor social support ${ }^{29}$

Unhealthy lifestyle ${ }^{30}$

\section{Does Psychotherapy for Depression Prevent Cardiac Events?}

The Enhancing Recovery in Coronary Heart Disease (ENRICHD) trial was a randomized trial of cognitive behavioral therapy vs usual care following MI. ${ }^{42}$ The study enrolled 2481 patients who had been hospitalized for MI within the past 30 days. Of these, 958 had major depression ( $\geq 5$ depressive symptoms for at least 2 weeks), 811 had minor depression (2-4 depressive symptoms for at least 2 weeks), 66 had dysthymia ( 3 or 4 dysthymic symptoms for at least 2 years), and 647 had low social support but no depression. Overall, the study found no difference in event-free survival between the intervention and control groups, although the cognitive behavioral therapy improved depression and social support.

Based on results of the ENRICHD study, one might reasonably conclude that psychotherapy does not improve cardiovascular outcomes. However, the usual care group had an unusually high recovery rate, suggesting that some patients may have had transient depressive symptoms related to the recent stress of an MI. Treating depression immediately after an MI event (when symptoms are more likely situational) may be less effective than targeting the subset of patients who have persistent depression 2 or 3 months later. Perhaps antidepressant therapy is more likely to decrease risk of future cardiovascular events in the subgroup of patients whose depressive symptoms have persisted for 2 or 3 months after MI than in all patients who are depressed immediately after MI. Moreover, intervention and control groups had equal access to pharmacotherapy, possibly diminishing the relative benefits of the psychosocial intervention. Indeed, a post hoc analysis of participants in the ENRICHD trial found that use of SSRIs was associated with $40 \%$ reductions in both recurrent MI and death, after adjustment for age, Killip class, ejection fraction, creati-nine levels, diabetes mellitus, CHF, previous MI, stroke, and baseline depressive symptoms. ${ }^{43}$

In summarizing the available evidence, recent Cochrane reviews have concluded there is not sufficient evidence that psychotherapy for depression improves outcomes in patients with $\mathrm{CHD},{ }^{44}$ and no study has examined whether treatment for depression improves outcomes in patients with CHF. ${ }^{45}$ Thus, although both psychological and pharmacological interventions reduce anxiety and depression, ${ }^{40,44}$ it remains unknown whether therapy for depression improves cardiovascular outcomes. A large randomized trial testing the effect of antidepressant medication on incidence or recurrence of cardiac events would help to answer this question. However, because patients with depression cannot be assigned to placebo, ethical considerations make designing such a trial challenging.

\section{What Is the Best Way to Diagnose Depression in a Patient With Heart Disease?}

Depression is present in approximately $5 \%$ of the general population, ${ }^{46} 10 \%$ of medical outpatients, ${ }^{47} 20 \%$ of outpatients with CHD, ${ }^{48} 30 \%$ to $40 \%$ of outpatients with heart failure, 49,50 and up to $50 \%$ of patients recently hospitalized for CABG surgery or acute coronary syndrome. ${ }^{51} \mathrm{~A}$ simple 2 -item instrument, which takes less than a minute to complete, is an effective screening tool for identifying depression in patients with heart disease (FIGURE 1). A "yes" response to one or both questions (a positive screen) is $90 \%$ sensitive and $69 \%$ specific 
for depression in patients with heart disease. ${ }^{52} \mathrm{~A}$ "no" response to both questions effectively rules out depression, and no further screening is necessary. ${ }^{52,53}$ However, the low specificity and low positive predictive value of the 2-item instrument means that less than half of patients who screen positive will ultimately meet criteria for depression. Thus, any positive screen must be followed by a clinician interview for depression (Figure 1). ${ }^{54,55}$

In a busy cardiology practice, where it may be less feasible to administer the 2-item screen followed by a clinical interview for those who screen positive for depression, an alternative approach is to administer the 9-item Patient Health Questionnaire (PHQ-9; FIGURe 2). ${ }^{53,56,57}$ The PHQ-9 is a self-report questionnaire that patients can fill out in the waiting room along with their registration paperwork or insurance forms. It takes less than 2 minutes to complete. An office assistant can add up the scores and alert the clinician if a patient scores 10 or higher. Although a cutpoint of 10 or higher on the PHQ-9 misses about half of depression cases in patients with CHD, its $90 \%$ specificity and high positive predictive value make it virtually diagnostic for depression. $3,53,56$ Thus, patients who screen positive for depression need not undergo a follow-up clinical interview to confirm the diagnosis. To minimize false-negatives, I prefer to use the 2 -item instrument and confirm any positive screening result with a clinical interview for depression. However, administering the PHQ-9 allows for easy detection of more than half of depression cases without the need for further confirmation.

\section{What About the Effects of Substance Abuse and Other Medications?}

Concurrent substance abuse (such as alcohol abuse in the case presented) is not a contraindication to antidepressant therapy. Indeed, use of antidepressant medication can reduce risk of relapse in smokers ${ }^{58}$ and in those with alcohol dependence. ${ }^{59}$ Some medications, such as corticosteroids, opioids, and benzodiazepines, can cause depression. However, contrary to conventional wisdom, $\beta$-blocker therapy does not cause depression. ${ }^{60}$

\section{How Should Depression Be Treated in Patients With Heart Disease?}

For initial treatment of depression, the choice of structured psychotherapy, medication therapy, or both depends on available resources and patient preferences. When discussing potential treatment options, it is helpful to emphasize the biological etiology of depression because many patients view a diagnosis of depression as a character weakness or personality flaw. In layperson's language, I often describe depression as an imbalance of brain chemicals that can be restored to normal with antidepressant therapy, just like diabetes results from an imbalance of glucose concentration that can be restored to normal with insulin. This helps patients recognize that depression is a biological condition for which effective treatments are available. I further explain treatment options by saying that taking antidepressant medication is like taking hypoglycemic medication for diabetes and that engaging in psychotherapy is like learning healthy diet and exercise habits for diabetes. I also tell patients that depression is very common (at least 1 in 5 patients with heart disease), that it is associated with adverse cardiac outcomes, and that treatment can make a big difference in their lives.

\section{Structured Psychotherapy}

In the hands of an experienced therapist, cognitive behavioral therapy (CBT) is a safe and effective treatment for depression in patients with heart disease. ${ }^{42}$ Typically provided in 16 weekly sessions, CBT focuses on identifying and modifying cognitive (eg, self-critical thoughts) and behavioral habits that may contribute to depression. The goal of CBT is to help patients develop new ways of thinking and behaving that minimize symptoms of depression. Interpersonal therapy (IPT) and problem-solving therapy, are also effective treatments for depression, ${ }^{61}$ but they have not been evaluated specifically for patients with heart disease. Interpersonal therapy addresses social and interpersonal stressors that may contribute to 
depression. Problem solving therapy helps patients identify and solve specific problems that may be contributing to their depression.

Evaluation of these therapies specifically in patients with heart disease is important because, although seemingly benign, psychotherapy is not necessarily risk free. The Montreal Heart Attack Readjustment Trial (M-HART) ${ }^{62}$ randomly assigned 1376 patients who had had an MI event to monthly telephone monitoring with or without additional evaluation and support for psychological distress. After the first year, the program had no overall effect on either survival or psychological outcomes, but investigators found higher cardiac and all-cause mortality among women who received the intervention. These findings raised concern that this particular psychosocial intervention may have increased rather than decreased distress by reminding participants of their disease state and diminishing their perceived health status.

An ongoing randomized controlled trial, CREATE (Interpersonal Therapy and Citalopram for Depression in Coronary Disease), is comparing the safety and efficacy of IPT, the SSRI antidepressant citalopram, or both vs standardized clinical management for treatment of depression in 280 patients with CHD. ${ }^{63}$ However, pending results of this trial, CBT is the only psychotherapy known to be safe and effective for treating depression in patients with heart disease. In patients with moderate to severe depression, treatment with the combination of antidepressant medication and CBT can enhance the likelihood of response over either alone, 64 and the benefits of CBT may endure even beyond the end of treatment. ${ }^{65}$

\section{Pharmacotherapy}

Selective serotonin reuptake inhibitors are safe and effective medications for depression in patients with heart disease. ${ }^{66}$ No evidence suggests that one SSRI is more effective than another. ${ }^{67}$ However, citalopram and sertraline are the least likely to inhibit cytochrome p450 enzymes, thus minimizing exposure to pharmacokinetic interactions in cardiac patients taking multiple drugs. ${ }^{68}$ One simple approach is for the clinician to become familiar with 1 of these 2 SSRIs and to use it as first-line treatment for all patients with newly diagnosed depression. For sertraline, the initial dose is $50 \mathrm{mg} / \mathrm{d}$, the usual effective dose is 100 to $150 \mathrm{mg} / \mathrm{d}$, and the maximum dose is $200 \mathrm{mg} / \mathrm{d}$. For citalopram, the initial dose is $20 \mathrm{mg} / \mathrm{d}$, the usual effective dose is 20 to $40 \mathrm{mg} / \mathrm{d}$, and the maximum dose is $60 \mathrm{mg} / \mathrm{d}$. Elderly patients or those with hepatic or renal disease should start with half of the recommended initial dose. More than $50 \%$ of patients will respond to initial treatment, and $80 \%$ will eventually respond to at least 1 antidepressant medication. ${ }^{69}$ There is no evidence that nonresponse to one SSRI predicts nonresponse to another SSRI, so if a patient has not responded to citalopram, for example, citalopram can be tapered off while sertraline is initiated.

The most commonly reported adverse effects of the SSRIs are insomnia or somnolence, nausea or diarrhea, and sexual dysfunction (decreased libido, erectile dysfunction, delayed ejaculation, or anorgasmia). Most adverse effects diminish over the first month of treatment, so it is important to encourage patients not to discontinue the medication immediately. However, sexual dysfunction occurs in up to $60 \%$ of patients treated with SSRIs and is the least likely adverse effect to resolve over time. ${ }^{70}$ Some patients with SSRI-induced sexual dysfunction derive benefit from sildenafil ${ }^{71}$ or feel that the improvement in depression outweighs any decline in sexual function. However, other patients may find that SSRI-induced sexual dysfunction is not tolerable.

For patients who cannot tolerate SSRI-induced sexual dysfunction or for patients who are planning to stop smoking, ${ }^{58,72}$ bupropion is an effective alternative. ${ }^{73}$ For bupropion, the initial dose is $100 \mathrm{mg}$ twice a day, the usual effective dose is $100 \mathrm{mg} 3$ times a day, and the maximum dose is $150 \mathrm{mg} 3$ times a day. For sustained-release bupropion, the initial dose is $150 \mathrm{mg} / \mathrm{d}$, the usual effective dose is $150 \mathrm{mg} 2$ times a day, and the maximum dose is $200 \mathrm{mg} 2$ times a 
day. Selective serotonin reuptake inhibitors and bupropion can be administered simultaneously. If being discontinued, however, SSRIs should be tapered over a 2-week period to avoid SSRI discontinuation syndrome, including dizziness, vertigo, headache, nausea, and insomnia. ${ }^{74}$ Of note, bupropion has been associated with minor increases in blood pressure,

${ }^{73}$ so blood pressure monitoring is recommended.

Regarding other antidepressant medications, mirtazapine is generally safe for patients with heart disease but is not a first-line therapy because it is associated with weight gain ${ }^{75}$ and because it can induce hypertensive urgency when administered with clonidine. ${ }^{76}$ Tricyclics should not be used as first-line therapy because of their association with adverse cardiovascular events. ${ }^{77}$ Likewise, hypericum perforatum (St John's wort) is not recommended due to its potential interactions with cardioactive medications. ${ }^{78}$ One open-label study found that nefazodone was safe, tolerable, and effective for the treatment of depression in 19 patients with CHF. ${ }^{79}$ However, no randomized trial has formally evaluated the safety or efficacy of antidepressant medication in patients with CHF.

\section{When Should Depressed Cardiac Patients Be Referred to a Psychiatrist?}

Before initiating antidepressant therapy for patients with heart disease, it is important to inquire about any history of manic symptoms (unusually elevated mood, increased energy, excitability, or irritability) because initiating antidepressant medication in a patient with unrecognized bipolar disorder may trigger a manic episode. Depressed patients with a history of mania or psychosis (delusions or hallucinations) should be referred to a psychiatrist for further evaluation and treatment. It is also important to ask about suicidal thoughts (eg, "Do you ever think of hurting yourself or taking your own life?"). If the answer is yes, this should be followed by, "Do you currently have a plan?" and, if yes again, "What is your plan?" 80 If there is concern that patients may harm themselves before seeking help, emergent psychiatric evaluation must be obtained.

\section{How Should Cardiac Patients Be Followed Up After Initiating Treatment for Depression?}

Close monitoring during the first 3 months of therapy is critical to the effectiveness of depression treatment. When starting psychotherapy or antidepressant medication, it is important to educate cardiac patients that they are not going to feel better overnight. Antidepressant medications typically take 2 to 4 weeks before symptoms begin to improve. About $40 \%$ of patients will have recovered by 6 weeks, $60 \%$ will have recovered by 12 weeks, and $80 \%$ will have recovered 6 months into therapy. ${ }^{81}$ Similarly, the clinical benefits of CBT may not be evident for 6 to 8 weeks, and recovery may take as long as 16 weeks. ${ }^{82}$ Organized follow-up programs that include patient education, telephone or in-person contact every 2 to 4 weeks, monitoring of medication adherence, and psychiatric consultation as necessary improve outcomes for depressed cardiac patients. ${ }^{83-86}$ "Measurement-based care," which uses frequent ratings of symptoms and adverse effects to guide dose adjustments and changes in treatment, can also be of benefit. ${ }^{87}$

If antidepressant medication does not improve symptoms by 4 weeks and adverse effects are tolerable, the initial medication dose should be doubled. If symptoms have not improved by 8 weeks and adverse effects still remain tolerable, the dose should again be increased to the maximum allowable dose. If no improvement has occurred by 12 weeks, the patient should be switched to a different medication or referred to a psychiatrist. Similarly, if CBT has not resulted in symptom improvement by 6 to 8 weeks, or full remission by 16 weeks, the addition of medication should be considered. Once a patient has responded to pharmaco-therapy, it must be continued for at least 6 months to prevent relapse. 
For many patients, major depressive disorder is a chronic condition with a lifetime of relapses and recurrences. A recent randomized trial ${ }^{88}$ evaluated the efficacy of maintenance treatment with IPT vs the SSRI paroxetine in 116 depressed patients 70 years or older who had responded to 24 weeks of initial treatment with both paroxetine and IPT. Although not specifically a population with heart disease, these study participants were elderly, and many had concurrent medical illnesses. During 2 years of follow-up, participants who received continuation therapy with paroxetine were less likely to develop recurrent depression than those who received placebo. However, continuation therapy with IPT was no more effective for preventing recurrence than clinical management, and the combination of IPT and paroxetine was no more effective than paroxetine alone. These results suggest that for older patients and for those with one or more prior episodes of depression, pharmacotherapy should be continued for at least 2 years and possibly indefinitely.

\section{SUMMARY}

Depression is present in 1 of 5 outpatients with CHD and in 1 of 3 out-patients with CHF. Evidence from observational studies suggests that depression independently predicts incident CHD events, CHF, and adverse outcomes among patients with established cardiovascular disease. Although no randomized trial has demonstrated that treatment for depression improves cardiovascular outcomes, observational data suggest that use of antidepressant medication is associated with a decreased risk of future events. In the case presented, the patient started an SSRI, experienced gradual resolution of his depressive symptoms over 1 to 2 months, and was free of depression 3 months after starting antidepressant therapy. He has continued taking the SSRI and remained free of both depression and cardiac events for the 2 years since his percutaneous revascularization. Whether treatment for depression 5 years earlier would have delayed or prevented his MI is not known. What we do know is that identifying depression in patients with heart disease is not difficult and that treatment alleviates depression and improves quality of life.

\section{QUESTIONS AND COMMENT}

A Physician Does any evidence show that patients who are taking SSRIs adhere to their cardiac medications more readily than other patients?

$\mathbf{D}_{\mathbf{R}} \mathbf{W}_{\text {ноöex }}$ No trial has evaluated the effect of SSRIs on medication adherence. And that is definitely the next step, to find out whether antidepressant therapy improves medication adherence - and cardiovascular outcomes - for patients with heart disease. Of course, it will be important to combine any trial of treatment for depression with organized followup programs that include patient education and close monitoring of adherence to antidepressant therapy.

A P Pysician What is the role of cardiac rehabilitation in terms of management of depression?

$\mathbf{D}_{\mathbf{R}} \mathbf{W}_{\text {нооцеу }}$ Cardiac rehabilitation has several important components, including training patients to exercise, to eat healthy foods, to adhere to preventive medications, and to reduce psychological distress. Cardiac rehabilitation is known to improve cardiovascular outcomes, and its psychological components may be partly responsible for these benefits.

A Physician So many depressed patients smoke. Why not just go to bupropion right away with those, and why not do that instead of SSRIs?

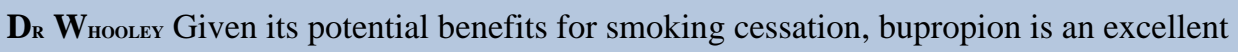
first choice for cardiac patients who smoke. The only reason I didn't recommend it as a first-choice antidepressant medication for all cardiac patients is that it can be associated with minor increases in blood pressure. Also, many clinicians find longer lists of 
antidepressant medications - with their specific indications and adverse effects—-so complicated that they end up not treating depression at all. My goal was to provide a practical approach that clinicians can easily incorporate in practice.

\section{Acknowledgments}

The author thanks Erin Hartman, MS, Department of Medicine, University of California, San Francisco, for her thoughtful comments on this manuscript. Ms Hartman did not receive compensation for her help.

Funding/Support: Dr Whooley was funded by the Department of Veterans Affairs Health Services Research and Development Service Career Development Program, the Robert Wood Johnson Foundation Generalist Physician Faculty Scholars Program, and the Paul Beeson Physician Faculty Scholars in Aging Research Program.

Role of the Sponsor: The funders did not participate in the preparation, review, or approval of the manuscript.

\section{REFERENCES}

1. Murray CJ, Lopez AD. Alternative projections of mortality and disability by cause 1990-2020: Global Burden of Disease Study. Lancet 1997;349:1498-1504. [PubMed: 9167458]

2. Wells, KB. Caring for Depression. Harvard University Press; Cambridge, Mass: 1996.

3. Diagnostic and Statistical Manual of Mental Disorders. Vol. 4th ed. American Psychiatric Association; Washington, DC: 2000. Text Revision

4. Lett HS, Blumenthal JA, Babyak MA, et al. Depression as a risk factor for coronary artery disease: evidence, mechanisms, and treatment. Psychosom Med 2004;66:305-315. [PubMed: 15184688]

5. Stewart RA, North FM, West TM, et al. Depression and cardiovascular morbidity and mortality: cause or consequence? Eur Heart J 2003;24:2027-2037. [PubMed: 14613739]

6. Barth J, Schumacher M, Herrmann-Lingen C. Depression as a risk factor for mortality in patients with coronary heart disease: a meta-analysis. Psychosom Med 2004;66:802-813. [PubMed: 15564343]

7. van Melle JP, de Jonge P, Spijkerman TA, et al. Prognostic association of depression following myocardial infarction with mortality and cardiovascular events: a meta-analysis. Psychosom Med 2004;66:814-822. [PubMed: 15564344]

8. Evans DL, Charney DS, Lewis L, et al. Mood disorders in the medically ill: scientific review and recommendations. Biol Psychiatry 2005;58:175-189. [PubMed: 16084838]

9. Borowicz L Jr, Royall R, Grega M, Selnes O, Lyketsos C, McKhann G. Depression and cardiac morbidity 5 years after coronary artery bypass surgery. Psychosomatics 2002;43:464-471. [PubMed: 12444229]

10. Yusuf S, Hawken S, Ounpuu S, et al. Effect of potentially modifiable risk factors associated with myocardial infarction in 52 countries (the INTERHEART study): case-control study. Lancet 2004;364:937-952. [PubMed: 15364185]

11. Abramson J, Berger A, Krumholz HM, Vaccarino V. Depression and risk of heart failure among older persons with isolated systolic hypertension. Arch Intern Med 2001;161:1725-1730. [PubMed: 11485505]

12. Williams SA, Kasl SV, Heiat A, Abramson JL, Krumholz HM, Vaccarino V. Depression and risk of heart failure among the elderly: a prospective community-based study. Psychosom Med 2002;64:612. [PubMed: 11818580]

13. Jiang W, Alexander J, Christopher E, et al. Relationship of depression to increased risk of mortality and rehospitalization in patients with congestive heart failure. Arch Intern Med 2001;161:1849-1856. [PubMed: 11493126]

14. Vaccarino V, Kasl SV, Abramson J, Krumholz HM. Depressive symptoms and risk of functional decline and death in patients with heart failure. J Am Coll Cardiol 2001;38:199-205. [PubMed: 11451275]

15. Rozzini R, Sabatini T, Frisoni GB, Trabucchi M. Depression and major outcomes in older patients with heart failure. Arch Intern Med 2002;162:362-364. [PubMed: 11822939] 
16. Carney RM, Blumenthal JA, Stein PK, et al. Depression, heart rate variability, and acute myocardial infarction. Circulation 2001;104:2024-2028. [PubMed: 11673340]

17. McCaffery JM, Frasure-Smith N, Dube MP, et al. Common genetic vulnerability to depressive symptoms and coronary artery disease: a review and development of candidate genes related to inflammation and serotonin. Psychosom Med 2006;68:187-200. [PubMed: 16554382]

18. Otte C, Marmar CR, Pipkin SS, Moos R, Browner WS, Whooley MA. Depression and 24-hour urinary cortisol in medical outpatients with coronary heart disease: The Heart and Soul Study. Biol Psychiatry 2004;56:241-247. [PubMed: 15312811]

19. Serebruany VL, Glassman AH, Malinin AI, et al. Enhanced platelet/endothelial activation in depressed patients with acute coronary syndromes: evidence from recent clinical trials. Blood Coagul Fibrinolysis 2003;14:563-567. [PubMed: 12960610]

20. Otte C, Neylan TC, Pipkin S, Browner WS, Whooley MA. Depressive symptoms and 24-hour urinary norepinephrine excretion levels in patients with coronary disease: findings from the Heart and Soul Study. Am J Psychiatry 2005;162:2139-2145. [PubMed: 16263855]

21. Schins A, Hamulyak K, Scharpe S, et al. Whole blood serotonin and platelet activation in depressed post-myocardial infarction patients. Life Sci 2004;76:637-650. [PubMed: 15567189]

22. Empana JP, Sykes DH, Luc G, et al. Contributions of depressive mood and circulating inflammatory markers to coronary heart disease in healthy European men: the Prospective Epidemiological Study of Myocardial Infarction (PRIME). Circulation 2005;111:2299-2305. [PubMed: 15867179]

23. Frasure-Smith N, Lesperance F, Julien P. Major depression is associated with lower omega-3 fatty acid levels in patients with recent acute coronary syndromes. Biol Psychiatry 2004;55:891-896. [PubMed: 15110732]

24. Strike PC, Steptoe A. Systematic review of mental stress-induced myocardial ischaemia. Eur Heart J 2003;24:690-703. [PubMed: 12713764]

25. Cohen HW, Gibson G, Alderman MH. Excess risk of myocardial infarction in patients treated with antidepressant medications: association with use of tri-cyclic agents. Am J Med 2000;108:2-8. [PubMed: 11059434]

26. Ziegelstein RC, Fauerbach JA, Stevens SS, Romanelli J, Richter DP, Bush DE. Patients with depression are less likely to follow recommendations to reduce cardiac risk during recovery from a myocardial infarction. Arch Intern Med 2000;160:1818-1823. [PubMed: 10871976]

27. Ruo B, Rumsfeld JS, Pipkin S, Whooley MA. Relation between depressive symptoms and treadmill exercise capacity in the Heart and Soul Study. Am J Cardiol 2004;94:96-99. [PubMed: 15219515]

28. Gehi A, Haas D, Pipkin S, Whooley MA. Depression and medication adherence in outpatients with coronary heart disease: findings from the Heart and Soul Study. Arch Intern Med 2005;165:25082513. [PubMed: 16314548]

29. Barefoot JC, Burg MM, Carney RM, et al. Aspects of social support associated with depression at hospitalization and follow-up assessment among cardiac patients. J Cardiopulm Rehabil 2003;23:404-412. [PubMed: 14646786]

30. Bonnet F, Irving K, Terra JL, Nony P, Berthezene F, Moulin P. Anxiety and depression are associated with unhealthy lifestyle in patients at risk of cardiovascular disease. Atherosclerosis 2005;178:339344. [PubMed: 15694943]

31. Carney RM, Freedland KE, Miller GE, Jaffe AS. Depression as a risk factor for cardiac mortality and morbidity: a review of potential mechanisms. J Psychosom Res 2002;53:897-902. [PubMed: 12377300]

32. Joynt KE, Whellan DJ, O'Connor CM. Why is depression bad for the failing heart? a review of the mechanistic relationship between depression and heart failure. J Card Fail 2004;10:258-271. [PubMed: 15190537]

33. Jiang W, Glassman A, Krishnan R, O'Connor CM, Califf RM. Depression and ischemic heart disease: what have we learned so far and what must we do in the future? Am Heart J 2005;150:54-78. [PubMed: 16084151]

34. Smith SC Jr, Blair SN, Bonow RO, et al. AHA/ACC Scientific Statement: AHA/ACC guidelines for preventing heart attack and death in patients with atherosclerotic cardiovascular disease: 2001 update: a statement for healthcare professionals from the American Heart Association and the American College of Cardiology. Circulation 2001;104:1577-1579. [PubMed: 11571256] 
35. Gibbons RJ, Abrams J, Chatterjee K, et al. ACC/AHA 2002 guideline update for the management of patients with chronic stable angina-summary article: a report of the American College of Cardiology/ American Heart Association Task Force on Practice Guidelines (Committee on the Management of Patients With Chronic Stable Angina). Circulation 2003;107:149-158. [PubMed: 12515758]

36. Hunt SA, Abraham WT, Chin MH, et al. ACC/AHA 2005 Guideline Update for the Diagnosis and Management of Chronic Heart Failure in the Adult-summary article: a report of the American College of Cardiology/American Heart Association Task Force on Practice Guidelines (writing committee to update the 2001 Guidelines for the Evaluation and Management of Heart Failure): developed in collaboration with the American College of Chest Physicians and the International Society for Heart and Lung Transplantation: endorsed by the Heart Rhythm Society. Circulation. 2005 112:e1825e1852.DOI:10.1161/circulationaha.105

37. Clinical Practice Guideline Number 5: Depression in Primary Care, 2: Treatment of Major Depression. US Dept of Health and Human Services, Public Health Service, Agency for Health Care Policy and Research; Rockville, Md: 1993. AHCPR publication 93-0551

38. Miller MD, Schulz R, Paradis C, et al. Changes in perceived health status of depressed elderly patients treated until remission. Am J Psychiatry 1996;153:1350-1352. [PubMed: 8831449]

39. Hill AB. The environment and disease: association or causation? Proc R Soc Med 1965;58:295-300. [PubMed: 14283879]

40. Glassman AH, O'Connor CM, Califf RM, et al. Sertraline treatment of major depression in patients with acute MI or unstable angina. JAMA 2002;288:701-709. [PubMed: 12169073]

41. Serebruany VL, Glassman AH, Malinin AI, et al. Platelet/endothelial biomarkers in depressed patients treated with the selective serotonin reuptake inhibitor sertraline after acute coronary events: the Sertraline AntiDepressant Heart Attack Randomized Trial (SADHART) Platelet Substudy. Circulation 2003;108:939-944. [PubMed: 12912814]

42. Berkman LF, Blumenthal J, Burg M, et al. Effects of treating depression and low perceived social support on clinical events after myocardial infarction: the Enhancing Recovery in Coronary Heart Disease Patients (ENRICHD) randomized trial. JAMA 2003;289:3106-3116. [PubMed: 12813116]

43. Taylor CB, Youngblood ME, Catellier D, et al. Effects of antidepressant medication on morbidity and mortality in depressed patients after myocardial infarction. Arch Gen Psychiatry 2005;62:792798. [PubMed: 15997021]

44. Rees K, Bennett P, West R, Davey SG, Ebrahim S. Psychological interventions for coronary heart disease. Cochrane Database Syst Rev. 2004;(2)CD002902

45. Lane DA, Chong AY, Lip GY. Psychological interventions for depression in heart failure. Cochrane Database Syst Rev. 2005;(1)CD003329

46. Hasin DS, Goodwin RD, Stinson FS, Grant BF. Epidemiology of major depressive disorder: results from the National Epidemiologic Survey on Alcoholism and Related Conditions. Arch Gen Psychiatry 2005;62:1097-1106. [PubMed: 16203955]

47. Hirschfeld RMA, Keller MB, Panico S, et al. The National Depressive and Manic-depressive Association consensus statement on the undertreatment of depression. JAMA 1997;277:333-340. [PubMed: 9002497]

48. Lesperance F, Frasure-Smith N. Depression in patients with cardiac disease: a practical review. J Psychosom Res 2000;48:379-391. [PubMed: 10880660]

49. Havranek EP, Ware MG, Lowes BD. Prevalence of depression in congestive heart failure. Am J Cardiol 1999;84:348-350. A9. [PubMed: 10496452]

50. Guck TP, Elsasser GN, Kavan MG, Barone EJ. Depression and congestive heart failure. Congest Heart Fail 2003;9:163-169. [PubMed: 12826775]

51. Ziegelstein RC. Depression in patients recovering from a myocardial infarction. JAMA 2001;286:1621-1627. [PubMed: 11585486]

52. McManus D, Pipkin SS, Whooley MA. Screening for depression in patients with coronary heart disease (data from the Heart and Soul Study). Am J Cardiol 2005;96:1076-1081. [PubMed: 16214441]

53. Whooley MA, Avins AL, Miranda J, Browner WS. Case-finding instruments for depression: two questions are as good as many. J Gen Intern Med 1997;12:439-445. [PubMed: 9229283] 
54. Whooley MA, Simon GE. Managing depression in medical outpatients. N Engl J Med 2000;343:1942-1950. [PubMed: 11136266]

55. Kroenke K. A 75-year-old man with depression. JAMA 2002;287:1568-1576. [PubMed: 11911760]

56. Kroenke K, Spitzer RL, Williams JB. The PHQ-9 validity of a brief depression severity measure. J Gen Intern Med 2001;16:606-613. [PubMed: 11556941]

57. Spitzer RL, Kruenke K, Williams JBW. Patient Health Questionnaire Primary Care Study Group. Validation and utility of a self-report version of PRIME-MD: the PHQ primary care study. JAMA 1999;282:1737-1744. [PubMed: 10568646]

58. Hurt RD, Sachs DP, Glover ED, et al. A comparison of sustained-release bupropion and placebo for smoking cessation. N Engl J Med 1997;337:1195-1202. [PubMed: 9337378]

59. Mason BJ, Kocsis JH, Ritvo EC, Cutler RB. A double-blind, placebo-controlled trial of desipramine for primary alcohol dependence stratified on the presence or absence of major depression. JAMA 1996;275:761-767. [PubMed: 8598592]

60. Ko DT, Hebert PR, Coffey CS, Sedrakyan A, Curtis JP, Krumholz HM. $\beta$-blocker therapy and symptoms of depression, fatigue, and sexual dysfunction. JAMA 2002;288:351-357. [PubMed: 12117400]

61. Skala, JA.; Freedland, KE.; Carney, RM. Heart Disease (Advances in Psychotherapy-EvidenceBased Practice). Hogrefe \& Huber; Cambridge, Mass: 2005.

62. Frasure-Smith N, Lesperance F, Prince RH, et al. Randomised trial of home-based psychosocial nursing intervention for patients recovering from myocar-dial infarction. Lancet 1997;350:473-479. [PubMed: 9274583]

63. Frasure-Smith N, Koszycki D, Swenson JR, et al. Design and rationale for a randomized, Controlled Trial of Interpersonal Psychotherapy and Citalopram for Depression in Coronary Artery Disease (CREATE). Psychosom Med 2006;68:87-93. [PubMed: 16449416]

64. Hollon SD, Jarrett RB, Nierenberg AA, Thase ME, Trivedi M, Rush AJ. Psychotherapy and medication in the treatment of adult and geriatric depression: which monotherapy or combined treatment? J Clin Psychiatry 2005;66:455-468. [PubMed: 15816788]

65. Hollon SD, DeRubeis RJ, Shelton RC, et al. Prevention of relapse following cognitive therapy vs medications in moderate to severe depression. Arch Gen Psychiatry 2005;62:417-422. [PubMed: 15809409]

66. Mann JJ. The medical management of depression. N Engl J Med 2005;353:1819-1834. [PubMed: $16251538]$

67. Kroenke K, West SL, Swindle R, et al. Similar effectiveness of paroxetine, fluoxetine, and sertraline in primary care: a randomized trial. JAMA 2001;286:2947-2955. [PubMed: 11743835]

68. Solai LK, Mulsant BH, Pollock BG. Selective serotonin reuptake inhibitors for late-life depression: a comparative review. Drugs Aging 2001;18:355-368. [PubMed: 11392444]

69. Schulberg HC, Katon W, Simon GE, Rush AJ. Treating major depression in primary care practice: an update of the Agency for Health Care Policy and Research Practice Guidelines. Arch Gen Psychiatry 1998;55:1121-1127. [PubMed: 9862556]

70. Zajecka J, Mitchell S, Fawcett J. Treatment-emergent changes in sexual function with selective serotonin reuptake inhibitors as measured with the Rush Sexual Inventory. Psychopharmacol Bull 1997;33:755-760. [PubMed: 9493488]

71. Taylor MJ, Rudkin L, Hawton K. Strategies for managing antidepressant-induced sexual dysfunction: systematic review of randomised controlled trials. J Affect Disord 2005;88:241-254. [PubMed: 16162361]

72. Jorenby DE, Leischow SJ, Nides MA, et al. A controlled trial of sustained-release bupropion, a nicotine patch, or both for smoking cessation. N Engl J Med 1999;340:685-691. [PubMed: 10053177]

73. Roose SP, Dalack GW, Glassman AH, Woodring S, Walsh BT, Giardina EG. Cardiovascular effects of bupropion in depressed patients with heart disease. Am J Psychiatry 1991;148:512-516. [PubMed: 1900980]

74. Tamam L, Ozpoyraz N. Selective serotonin reuptake inhibitor discontinuation syndrome: a review. Adv Ther 2002;19:17-26. [PubMed: 12008858] 
75. Stimmel GL, Dopheide JA, Stahl SM. Mirtazapine: an antidepressant with noradrenergic and specific serotonergic effects. Pharmacotherapy 1997;17:10-21. [PubMed: 9017762]

76. Abo-Zena RA, Bobek MB, Dweik RA. Hypertensive urgency induced by an interaction of mirtazapine and clonidine. Pharmacotherapy 2000;20:476-478. [PubMed: 10772378]

77. Roose SP. Treatment of depression in patients with heart disease. Biol Psychiatry 2003;54:262-268. [PubMed: 12893102]

78. Zellweger MJ, Osterwalder RH, Langewitz W, Pfisterer ME. Coronary artery disease and depression. Eur Heart J 2004;25:3-9. [PubMed: 14683736]

79. Lesperance F, Frasure-Smith N, Laliberte MA, et al. An open-label study of nefazodone treatment of major depression in patients with congestive heart failure. Can J Psychiatry 2003;48:695-701. [PubMed: 14674053]

80. Miller, MC. Suicide assessment in the primary care setting. In: Jacobs, DG., editor. The Harvard Medical School Guide to Suicide Assessment and Intervention. Jossey-Bass Publishers; San Francisco, Calif: 1999. p. 520-539.

81. Kupfer DJ, Frank E, Perel JM. The advantage of early treatment intervention in recurrent depression. Arch Gen Psychiatry 1989;46:771-775. [PubMed: 2774846]

82. DeRubeis RJ, Hollon SD, Amsterdam JD, et al. Cognitive therapy vs medications in the treatment of moderate to severe depression. Arch Gen Psychiatry 2005;62:409-416. [PubMed: 15809408]

83. Katon W, Von Korff M, Lin E, et al. Collaborative management to achieve treatment guidelines: impact on depression in primary care. JAMA 1995;273:1026-1031. [PubMed: 7897786]

84. Wells KB, Sherbourne CD, Schoenbaum M, et al. Impact of disseminating quality improvement programs for depression in managed primary care: a randomized controlled trial. JAMA 2000;283:212-220. [PubMed: 10634337]

85. Unutzer J, Katon W, Callahan CM, et al. Collaborative care management of late-life depression in the primary care setting: a randomized controlled trial. JAMA 2002;288:2836-2845. [PubMed: 12472325]

86. Koike AK, Unutzer J, Wells KB. Improving the care for depression in patients with comorbid medical illness. Am J Psychiatry 2002;159:1738-1745. [PubMed: 12359681]

87. Trivedi MH, Rush AJ, Wisniewski SR, et al. Evaluation of Outcomes With Citalopram for Depression Using Measurement-Based Care in STAR*D: implications for clinical practice. Am J Psychiatry 2006;163:28-40. [PubMed: 16390886]

88. Reynolds CF III, Dew MA, Pollock BG, et al. Maintenance treatment of major depression in old age. N Engl J Med 2006;354:1130-1138. [PubMed: 16540613] 


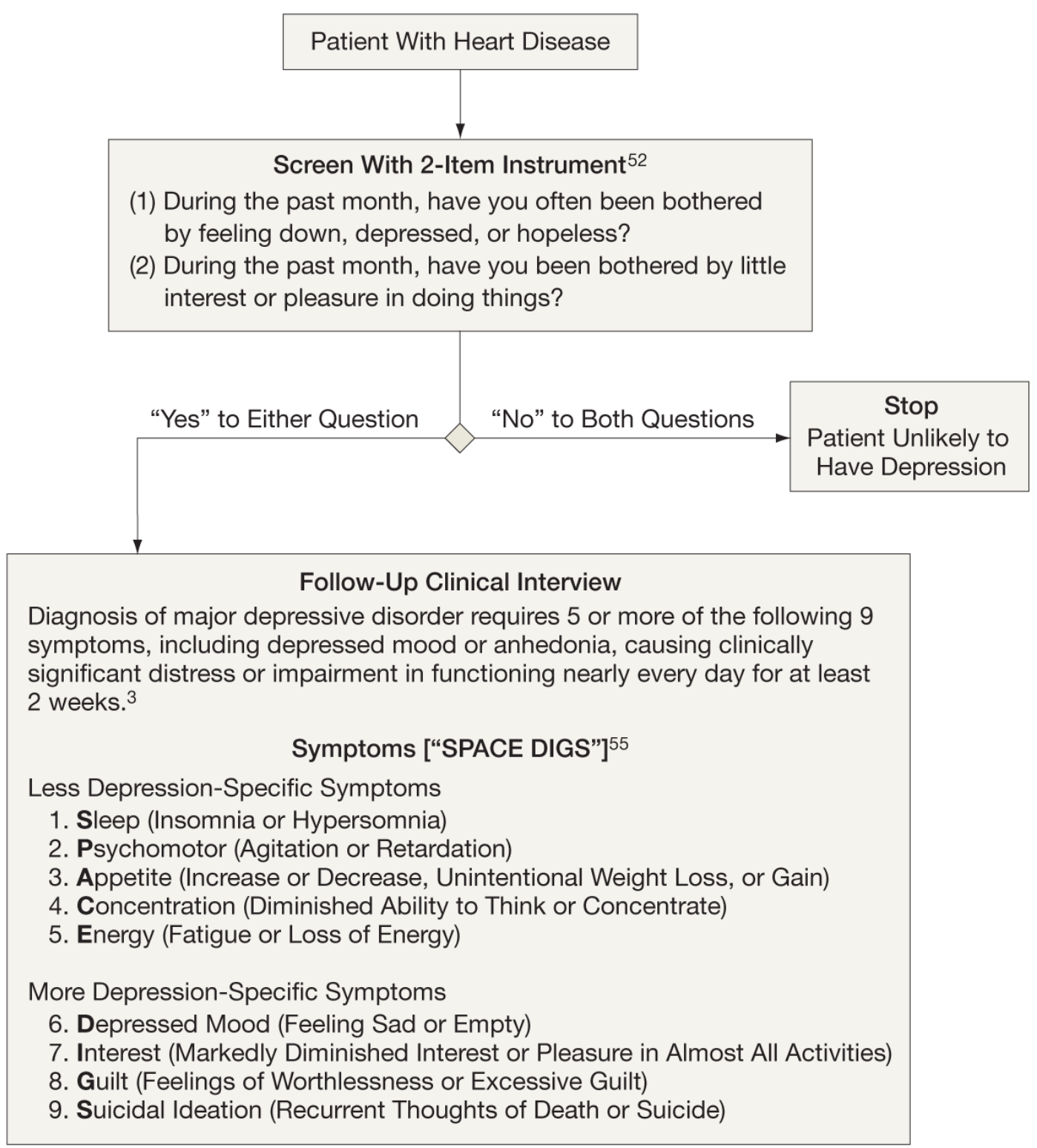

Figure 1.

Diagnosing Depression in Patients With Heart Disease 
NAME:

DATE:

Over the last 2 weeks, how often have you been bothered by any of the following problems? (use "y" to indicate your answer)

1. Little interest or pleasure in doing things

2. Feeling down, depressed, or hopeless

3. Trouble falling or staying asleep, or sleeping too much

4. Feeling tired or having little energy

5. Poor appetite or overeating

6. Feeling bad about yourself - or that you are a failure or have let yourself or your family down

7. Trouble concentrating on things, such as reading the newspaper or watching television

8. Moving or speaking so slowly that other people could have noticed. Or the opposite - being so fidgety or restless that you have been moving around a lot more than usual

9. Thoughts that you would be better off dead or of hurting yourself in some way

add columns:

TOTAL:

The PHQ-9 copyright 1999 Pfizer Inc. All rights reserved. Reproduced with permission. Use of the PHQ-9 may be made in accordance with the terms of use available at http://www.pfizer.com/pfizer/phq-9/index-jsp.

Figure 2.

The 9-Item Patient Health Questionnaire Depression Screening Instrument 